\title{
URNOVÉ POHREBISKO V PODTURNI VO SVETLE VÝSKUMU JULIUSA NEUDECKA*
}

\author{
GABRIEL NEVIZÁNSKY - PÉTER PROH ÁSZKA
}

\author{
Ad multus annos Jozef Bátora!
}

\begin{abstract}
The Urn Cemetery of the Lusatian Culture at Podtureň in the Mirror of the Excavation of Julius Neudeck. The article deals with a report and a drawing of Julius Neudeck. They are in the legacy of Friedrich Kenner in Vienna. Neudeck had reported about a burial-ground in the vicinity of Podtureň (county Liptov). His drawing shows a pottery urn, bronze tools and a map of the cemetery. Neudeck (1835-1909) was an amateur archaeologist of Austrian origin. He lived after his military service in Podtureň, but after the 1890s he was an Engineer in Serbia and later a consular clerk in Sofia. His report for Kenner is an important source about the cemetery of Podtureň. Thanks to his drawings, it was possible to evaluate the finds. They belong to the pre-Lusatian culture and the early phase of the Lusatian culture.
\end{abstract}

Keywords: Slovakia, Lusatian culture, Julius Neudeck, archival records, prehistory.

\section{ÚVOD}

Výskum archeologických pamiatok v Podturni, okr. Liptovský Mikuláš sa začal v 70. rokoch 19. stor., kedy sa pri stavbe Košicko-bohumínskej železnice a iných zemných prácach začali objavovat’ artefakty z rôznych období praveku a včasnej doby dejinnej (Furman 2016, 188-207). K týmto nálezom patrí aj urnové pohrebisko, ktoré objavili v roku 1871 počas výstavby železničnej trate $\mathrm{v}$ katastri obce. O pohrebisku bolo následne publikovaných niekol'ko súdobých výskumných správ. Napríklad B. Majláth (1873) v časopise Archaeologiai Közlemények nálezisko lokalizoval do katastra obce Uhorská Ves, okr. Liptovský Mikuláš. Následne v roku 1880 publikoval informácie o pohrebisku na stránkach viedenského periodika Mittheilungen der Antropologischen Gesellschaft J. Neudeck. Vtedajšie výskumné správy boli publikované aj v ročenke Ungarisches Karpathen-Verein od J. Mihalika (1889), ktoré boli písané na základe Majláthových podkladov. Hoci o nálezových okolnostiach disponujeme podrobnými opismi, kresby nálezov nie sú zverejnené a absentujú i konštrukčné detaily o hroboch.

Avšak o výskume v Podturni sa zachovali pramene vo viedenskej pozostalosti Friedricha Kennera. Julius Neudeck vo svojom liste pre tzv. Chronik der archäologischen Funde der österreichischen Monarchie zhrnul dovtedy známe nálezy a náleziská z územia Liptovskej stolice (Nevizánsky/ Prohászka, v tlači). Uvedená kronika nálezov už vtedy mala takmer štvrtstoročnú minulost̉ a stala sa jedným z najdôležitejších prameňov archeolo- gických nálezov nájdených na niekdajšom území Rakúsko-uhorskej monarchie. Jej zakladatelom, prvým redaktorom a autorom bol správca cisársko-královského Numizmaticko-archeologického kabinetu Johann Gabriel Seidl (1804-1875), ktorý v roku 1846 začal vydávat' viac-menej pravidelne na stránkach Österreichische Blätter für Literatur und Kunst a neskôr v časopise Archiv für Kunde österreichischer Geschichts-Quellen svoj „Chronik der archäologischen Funde in der österreichischen Monarchie" (Seidl 1846). Vd’aka priebežne vychádzajúcim správam aj čitatelia menovaných periodík informovali Seidla o archeologických nálezoch nájdených na rôznych miestach, ktoré vtedy zväčša putovali do súkromných zbierok. Od polovice 50. rokov 19. stor. prevzal od Seidla redakciu kroniky nálezov jeho spolupracovník a vynikajúci numizmatik Friedrich Kenner (1834-1922) a pokračoval v nej až do roku Rakúsko-uhorského vyrovnania (Kenner 1860; 1867). F. Kenner už počas štúdia na viedenskej univerzite začal pracovat $v$ Numizmaticko-archeologickom kabinete, kde ho v roku 1862 vymenovali za jeho kustóda. Medzi rokmi 1883-1899 vykonával dokonca funkciu jeho riaditela. Špecializoval sa hlavne na archeologické a numizmatické bádanie obdobia Rímskej ríše (Lhotsky 1945, 545-547). Posledná kronika archeologických nálezov vyšla v roku 1867, kde boli zozbierané informácie o nových nálezoch za roky 1864-1866 (Kenner 1867). V dôsledku politických a štátoprávnych zmien sa nové súpisy už nepublikovali. Napriek tomu v Kennerovej pozostalosti, ktorá sa dnes nachádza v Kunsthistorisches Museum, sa zachovali d’alšie

\footnotetext{
* Práca bola napísaná v rámci grantového projektu VEGA 2/0062/21.
} 


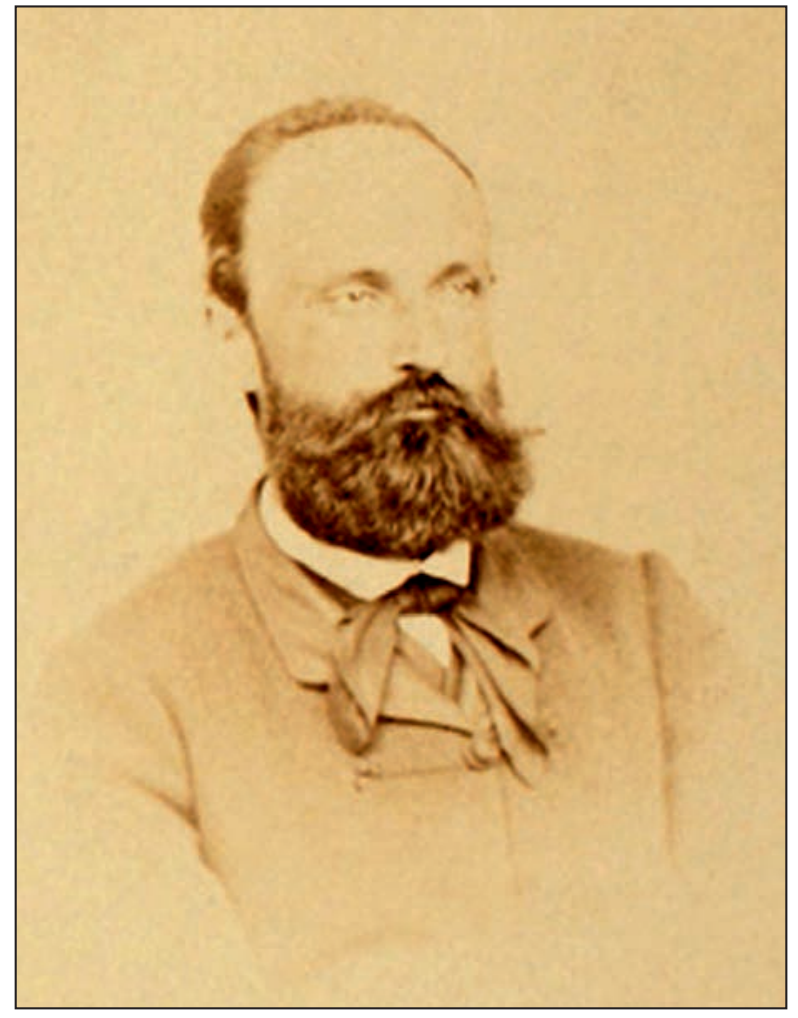

Obr. 1. Portrét Juliusa Neudecka (Országos Széchenyi Könyvtár, Budapest).

nepublikované hlásenia zo 70. rokov 19. stor. Zrejme ich nad’alej zhromaždoval pre prípadnú d’alšiu publikáciu (Nevizánsky/Prohászka, v tlači). Medzi uvedenými spismi sa nachádza aj spomenutý list Juliusa Neudecka datovaný k 18. novembru 1871, ktorý obsahuje informácie o liptovských nálezoch a archeologických lokalitách. K uvedenému spisu bola pripojená ilustrácia s farebnými kresbami.

\section{JULIUS NEUDECK, ODUŠEVNENÝ AMATÉRSKY ARCHEOLÓG LIPTOVA}

Julius Neudeck (Gyula Neudeck) sa zapísal do dejín archeologického a numizmatického bádania početnými príspevkami, ktoré zverejňoval v súdobých domácich odborných časopisoch Archaeologiai Értesítő a Archaeologiai Közlemények (Neudeck 1883; 1889; 1894; 1901) a v rakúskych periodikách Numismatische Zeitschrift, a Mittheinlung der Anthropologischen Gesellschaft in Wien (Neudeck 1879; 1880). Tažiskom jeho bádania bola Liptovská stolica, ale v neskorších prácach sa venoval aj rímskym pamiatkam Srbska (Neudeck 1879; 1880; 1883; 1894).

Ojeho biografii boli doteraz $\mathrm{k}$ dispozícii pomerne skromné údaje (Polla 1996, 212-219). Na požiadanie
Flórisa Rómera začiatkom 70. rokov 19. stor. mu poslal svoj životopis, avšak ten sa neskôr stratil (Rómer 1870). V Rómerovej pozostalosti (Országos Széchényi Könyvtár, Budapest; Fol Hung 1110) sa dnes nachádza iba Neudeckova fotografia (obr. 1). Vd’aka Neudeckovej vojenskej a diplomatickej činnosti je možné rekonštruovat jeho životné osudy na základe zachovaných dokumentov vo viedenskom Kriegsarchive (OeStA/KA Personalunterlagen, Grunbuchsevidenzen, Pionierkorps, 1851-55. 28. Heft, 5 Folio, Kt. 2442), ako i osobných kartónov v Haus-, Hof- und Staatsarchive (OeStA/MdA AdmReg Personalunterlagen Folio 4 Neudeck). Na základe týchto dokumentov sa J. Neudeck narodil vo Viedni v roku 1835 s katolíckym vierovyznaním. V roku 1850 sa prihlásil ako dobrovolník do rakúskej armády, kde pôsobil ako ženista do roku 1862, kedy odišiel v hodnosti kapitána do civilu. Za zásluhy v talianskom taž̌ení ho vyznamenali vojenským záslužným krížom s vojnovou dekoráciou. Následne po demobilizácii žil v Linci, neskôr sa oženil a odsṫahoval sa na Liptov.

Z korešpondencie medzi amatérskym archeológom Ferencom Ebenhochom, farárom z Koroncó a Flórisom Rómerom sa dozvedáme, že J. Neudeck sa na jar v roku 1867 stal statkárom v Podturni a že archeologické pamiatky zbieral už počas svojho pôsobenia v Linci (Csécs 2019, 85). Podturniansky statok opustil v roku 1890 a následne ako inžinier sa štyri roky podielal na regulačných prácach Dunaja pri Železných vrátach. V roku 1895 sa spolu so svojou manželkou prestahoval do Sofie, kde pôsobil až do svojej smrti. Najskôr vo funkcii konzulárneho úradníka a neskôr vo funkcii čestného úradníka vel'vyslanectva. Svoju zberatel'skú činnost’ však nezanechal, o čom svedčia napríklad príspevky v Archaeologiai Értesítő, v ktorých zverejňoval informácie o nálezoch mincí z územia niekdajšej dolnej Moesie (Neudeck 1901). J. Neudeck zomrel v Sofii 11. júna 1909, kde ho následne 12. júna pochovali s vojenskými poctami na tunajšom katolíckom cintoríne.

\section{INFORMÁCIE JULIUSA NEUDECKA O NÁLEZOCH A NÁLEZISKU V PODTURNI}

J. Neudeck žil takmer 25 rokov (od polovice 60. rokov do roku 1890) na Liptove, na svojom statku v Podturni, kde získal početné archeologické a numizmatické pamiatky a realizoval viaceré amatérske výskumy. Žial', o osude jeho súkromnej zbierky, v ktorej boli vo významnej miere zastúpené aj nálezy z Podturne, nemáme k dispozícii spolahlivé údaje. Nemožno však vylúčit, že obohatili zbierky niektorého západoeurópskeho múzea. Z hladiska 
opisu nájdených predmetov na urnovom pohrebisku v Podturni a jeho výskumu má nesmierne dôležitú informačnú hodnotu list s kresbami, datovaný k novembru 1871:

Pottornya Liptauer Comitat. Bei Gelegenheit des Eisenbahnbaues 1871 wurden im Materialgraben an der Augrischdorfer Hottergränze 1-4 unter dem Anschwemmboden eines fast daran liegenden Berges 25 Urnen, in unregelmässigen Entfernungen in einer 4-6" dicken Aschen u Kohlenschichte gefunden.

Die westlich an einer Art Mauer 1:6' breit u 2-3' hoch:/ gelegenen Urnen scheinen vermöglicheren oder vornehmeren gehört zu haben, da darin Bronzegegenstände sich befanden, in den östlichen aber mit Ausnahme einer einzigen, worin eine kleine bronz Spiral 1/4 im Durchmesser u 1" lang, war, nichts als Knochen gefunden wurden.

Sämmtliche Urnen waren vom Erddruck $u$ der Feuchtigkeit geborsten, haben 6" Mundöffnung, 6" Höhe gebaucht, ohne Henkel, mit einfachen Strichornamenten geschmückt, einige mit Graphit bestrichen, jede mit einem glatten Stein bedeckt und bis an die Mündung mit Knochen gefüllt, an letzteren glaube ich Brandspuren zu bemerken.

6 Urnen wurden in meiner Gegenwart gehoben.

In 8 Urnen fand man folgende Gegenstände:

6 Nadeln Fig. 1. 2. 3. 4 die 5 u 6 kam mir nicht zu Gesicht. 1 Ring Fig. 5.

3 Ohrringe Fig. 6. 7. 8.

2 Bruchstücke v. Bronze. Fig. 9 u. 10.

1 Glasperle)

1 Stück Glas) sehr porös Fig. 11 u. 12.

1 Knochenperle Fig. 13.

1 kleine Spirale von den Leuten zerzogen

1 Bronze Bruchstück wie eine hohle Spitze aussehend vieleicht Stück einer Pfeilspitze Fig. 14.

Kleines Urnchen Fig. 15.

Eine Urne aber verdient besonders bemerkt zu werden da selbe unter besonderen Umständen vorkam, sie war in der Wänden stärker 1/2", statt dem glatten Stein war selbe mit einen 5" hohen u 12" breiten mit Knochen gefüllten Schüssel bedeckt, auch stand selbe nicht so wie die anderen auf der Erde sondern wieder in einer ähnlichen Schüssel. Im Knochengefüllt.

Innern war umgekehrt u leer eine kleine Urne Fig. 15. 3" breit u 3" hoch mit netten Punktornamenten 3 Buken u abgebrochenen Henkeln mit Graphit geschwärzt, ferner eine 15" lange rundgebogene Bronzenadel und ein Fingerring in 3 Spiralen leider waren auch diese Schüsseln und Urne zerquetscht.

Sämmtliche 15 gefundenen Gegenstände befinden sich in meinem Besitz.

Die Patina ist theilweise eine sehr schöne zu nennen, leichtgrün meistens aber durch Sand $u$ Erde verunreinigt Fig. 2. ein neuer Bruch.

\section{Vol'ný preklad a štylisticky upravený a doplnený text listu}

Podtureň, Liptovská stolica. Počas výstavby železnice v roku 1871 na rozhraní chotárov s Uhorskou Vsou v tažobnej jame v híbke 1 až 4 siah (cca 2-8 m), tesne pod eróznou vrstvou hliny z blízkeho kopca, v nepravidelných vzdialenostiach od seba, vo vrstve popola a uhlíkov 4 až 6 palcov (cca $10-15 \mathrm{~cm}$ ) hrubej sa našlo 25 urien.

Západne od akéhosi múrika, širokého 6 stôp (cca $190 \mathrm{~cm}$ ) a 2-3 stopy (cca 63-95 cm) vysokého, sa nachádzali bohatšie urny, ktoré obsahovali aj bronzové predmety. Vo východnejšie situovaných urnách okrem jednej výnimky, kde sa našla bronzová špirála dlhá 1 palec $(\mathrm{cca} 2,5 \mathrm{~cm}) \mathrm{s}$ priemerom $1 / 4$ palca (cca $0,6 \mathrm{~cm}$ ), sa nachádzali iba kostičky.

Všetky urny boli v dôsledku vlhkosti a tlaku zeminy roztlačené. Boli bezuché, mali baňaté steny a ich výška dosahovala až 6 palcov (cca $15 \mathrm{~cm}$ ), zhodné rozmery mali ajústia. Ryhovaná-žliabkovaná výzdoba nádob bola jednoduchá, niektoré z nich mali grafitový povlak. Každú urnu prekrýval plochý kameň a bola vyplnená až po ústie kostičkami so stopami žiaru.

Šest' urien vyzdvihli v mojej prítomnosti.

V ôsmich urnách našli nasledovné predmety:

- šest̉ ihlíc (obr. 2: 1-4) - piatu a šiestu som nevidel;

- jeden prsteň (obr. 2: 5);

- tri náušnice (obr. 2: 6-8);

- dva bronzové fragmenty (obr. 2: 9, 10);

- jeden sklenený korálik;

- jedno sklíčko vo velmi skorodovanom stave (obr. 2: 11, 12);

- jeden korálik z kosti (obr. 2: 13);

- jedna drobná špirála, ktorú robotníci vytiahli;

- jeden dutý zašpicatený bronzový predmet, možno ide o čast' hrotu šípa (obr. 2: 14);

- malá urna (obr. 2: 15).

Jedna urna si zasluhuje zvláštnu pozornost', pretože sa našla za zvláštnych okolností. Hrúbka jej steny bola väčšia ako $1 / 2$ palca (cca 1,25 cm). Namiesto hladkého kameňa bola prikrytá misou plnou kostí, $\mathrm{s}$ výškou 5 palcov (cca 12,5 cm) a šírkou 12 palcov (cca $30 \mathrm{~cm}$ ). Urnu nepoložili na zem, ale na podobnú misu, ktorá tiež obsahovala kosti. V urne sa našiel prázdny, hore dnom uložený džbánok s čiernym grafitovým povlakom, odlomeným uchom, s tromi výčnelkami a pravidelným bodkovaným ornamentom (obr. 2: 15). Džbán mal výšku aj šírku 3 palce (cca 7,5 cm). V urne sa okrem kostí našla 15 palcov dlhá ihlica (cca $37-38 \mathrm{~cm}$ ) ohnutá do kruhu a prsteň v podobe trojnásobnej špirály. Žial', tieto misy a urna boli pod tlakom zeminy rozpučené.

Všetkých 15 nájdených predmetov je uložených v mojej zbierke. Svetlozelená patina je pekne 


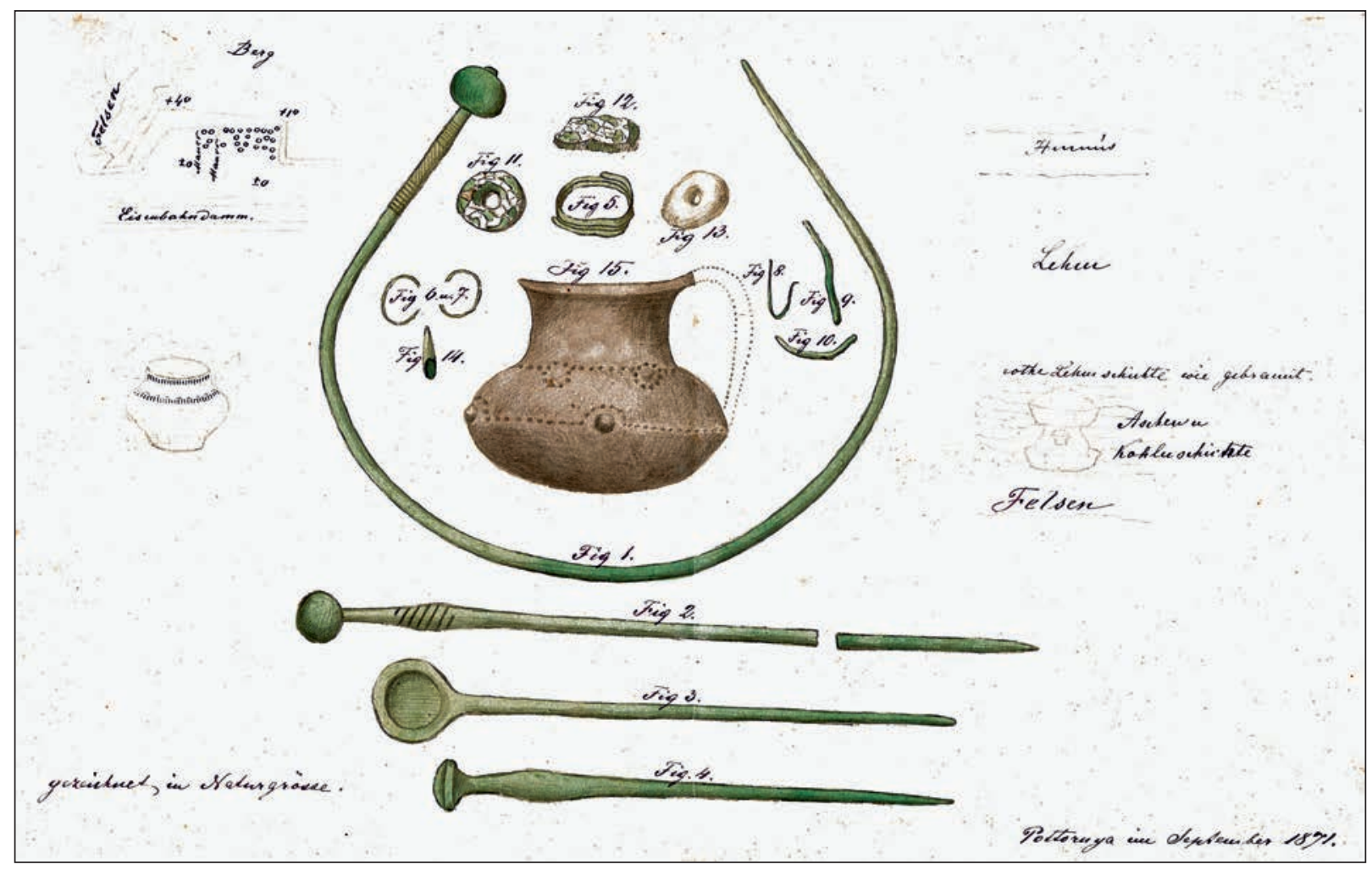

Obr. 2. Podtureň. Neudeckove kresby nálezov a pohrebiska (Kunsthistorisches Museum, Wien).

zachovaná, ale je od piesku a hliny zašpinená. Ihlica na obr. 2: 2 má čerstvý lom.

Julius Neudeck sa v tejto krátkej správe odvoláva na obrázky zobrazené na ilustrácií pripojenej k predmetnému listu (obr. 2). Na rozdiel od B. Majláthom $(1873,55$, obr. 9: 56; 10) publikovaných kresieb, Neudeckove obrázky sú dostatočne autentické a stávajú sa vhodným podkladom pre ich odborné vyhodnotenie.

\section{URNOVÉ POHREBISKO V PODTURNI}

Julius Neudeck sa po liste odoslanom v roku 1871 opät vrátil $\mathrm{k}$ nálezisku a nálezom $\mathrm{z}$ Podturne $\mathrm{v}$ roku 1880, ked' publikoval svoj príspevok na stránkach viedenskej antropologickej spoločnosti. K svojej štúdii síce dodal mapovú prílohu (obr. 3), ale nezverejnil kresby hrobov, resp. hrobových nálezov. Jeho relatívne podrobná správa o výskume v Podturni spolu s Majláthovou štúdiou sú dôležitým prameňom o pohrebisku. O hroboch nájdených v roku 1871 na ploche 50 štvorcových siah (cca $200 \mathrm{~m}^{2}$ ) síce informuje Béla Majláth $(1873,55,56)$ odbornú verejnost', ale mlčí o dalších zistených dôležitých detailoch a poznatkoch. Nezmieňuje sa napríklad o kameňoch pokrývajúcich urny a ani o nájde- nom múre, ktorý s najväčšou pravdepodobnostou môžeme považovat' za zvyšok kamenného venca mohyly. Na Neudeckovej kresbe je dobre vidiet' situovanie nádob, resp. $z$ bočného pohladu spôsob uloženia urien v hrobe. Na rozdiel od Majlátha $(1873,56)$, ktorý preferoval datovanie náleziska do doby bronzovej, Neudeck $(1880,57)$ sa už prikláňa $\mathrm{k}$ mladšiemu datovaniu, a to do doby železnej. $\mathrm{Na}$ báze svojich typologických a technologických analýz sledované pohrebisko kladie až do neskorej doby železnej, do obdobia rímskeho cisárstva. Naštastie jeho zachované kresby umožňujú nanovo analyzovat' nájdené predmety a tým aj spresnit’ a korigovat' predchádzajúce datovania.

\section{ANALÝZA HROBOVÝCH NÁLEZOV Z PODTURNE}

Kolekcia predmetov zobrazená na kresbe reprezentuje predovšetkým výnimočný súbor nájdených nekeramických nálezov, ktoré pochádzajú z devastovaných hrobov pohrebiska so žiarovým pohrebným rítom (obr. 2). V žiadnom prípade nejde o artefakty z uzavretého nálezového celku, ale o zobrazenie prevažne bronzových, resp. sklených (?) predmetov pochádzajúcich z urnových hrobov. Hoci väčšinu zachránených predmetov tvorila ke- 


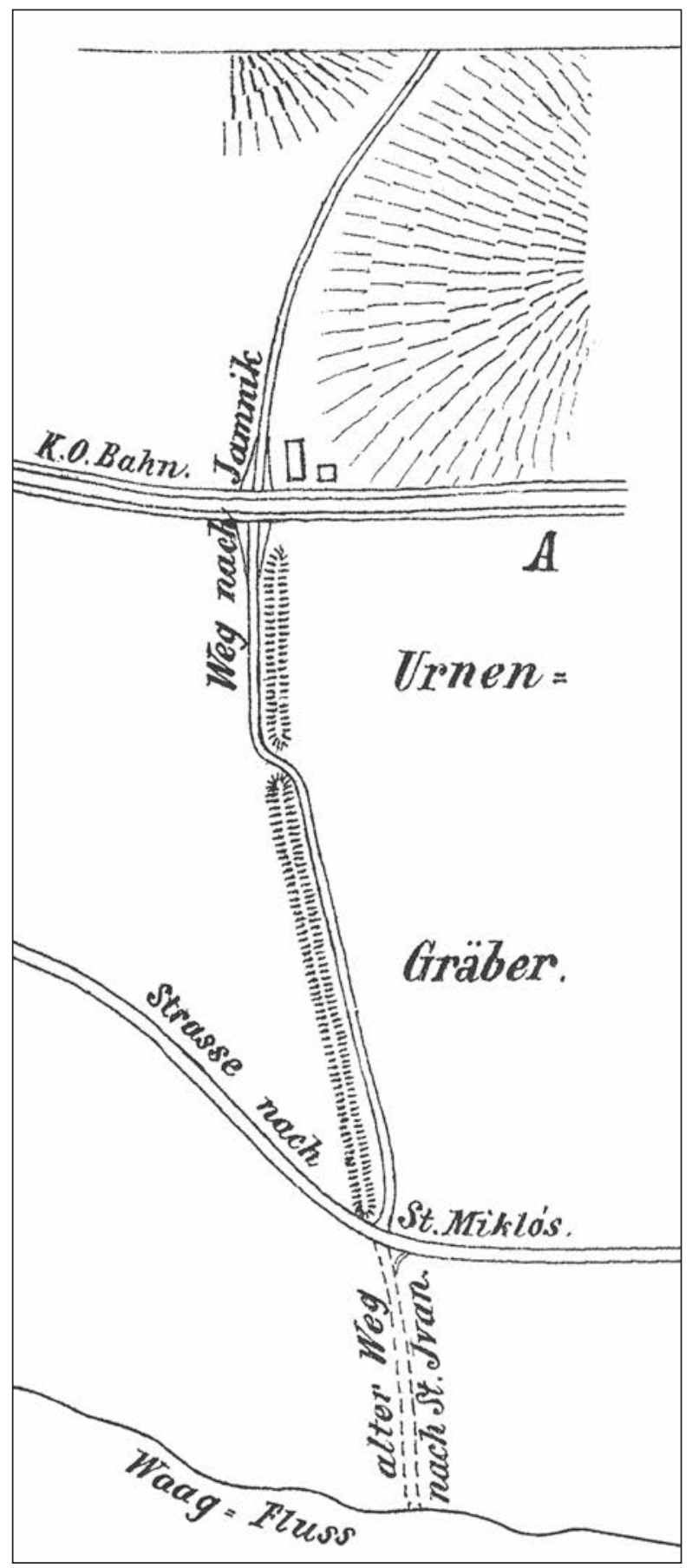

Obr. 3. Podtureň. Situačný plán náleziska (podl’a Neudeck 1880, obr. 3).

ramika, na kresbe je zobrazený iba jeden džbánok s odlomeným uchom zdobený tromi výčnelkami a bodkovanou výzdobou. Na základe vyobrazených nálezov možno konštatovat', že na sledovanom pohrebisku sa pochovávalo priebežne, resp. s prestávkami niekol'ko storočí. Ide o pohrebisko ležiace bezprostredne $\mathrm{v}$ podhradí Velímka, ktoré narušili pri stavbe Košicko-buhumínskej trate. J. Neudeck na lokalite, nachádzajúcej sa len pár desiatok metrov od kúrie, kde žil so svojou manželkou Emmou, odkryl celkom 25 popolníc zo zvyškami spálených kostí a popola. Niektoré urny obsahovali bronzové ihlice a ich fragmenty, prstene, náušnice, špirály, koráliky zo skla a kosti. B. Majláth (1873, 54-57) uvedené pohrebisko podrobne opisuje a kladie do katastra obce Uhorská Ves. Táto lokalizácia sa objavuje aj v neskorších prácach (Eisner 1933, 132, 133; Majláth 1873, 54-57; Mihalik 1889, 51, 52; Neudeck 1880, 56; Vitek/Churý/Struhár 2002, 8).

$\mathrm{Z}$ nakreslených predmetov si najväčšiu pozornost' zasluhuje hlinený džbánok $\mathrm{s}$ odlomeným uchom, baňatým telom, valcovitým hrdlom a lievikovite roztvoreným ústím. Nádobu zdobili na vydutine, resp. na rozhraní hrdla a tela, obežné horizontálne rady vpichov. Na vydutine nádoby sú symetricky rozmiestnené tri nízke, pravdepodobne polgul'ovité výčnelky, lemované vpichmi usporiadanými do poloblúka. Na rozhraní hrdla a tela sú tiež nízke výčnelky, dokola lemované vpichmi (obr. 2: 15).

Uvedený keramický tvar však nepatrí do náplne lužickej kultúry, ale reprezentuje osídlenie lokality ešte v období pred kryštalizáciou uvedenej kultúry - tzv. predlužický horizont. Na základe analógií zo západného Slovenska možno usúdit, že dokumentuje migráciu obyvatel'stva $z$ juhu na sever, do oblastí severného Slovenska. Najbližšia analógia

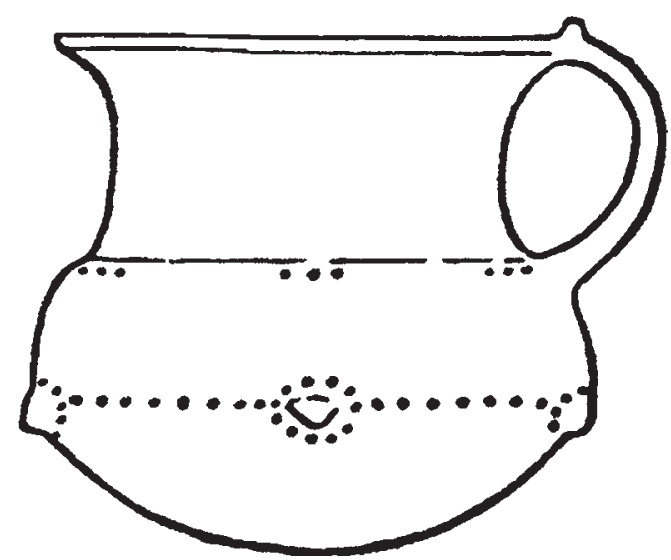

Obr. 4. Džbán z hrobu 143 zo Salky (podl’a Točík 1964, obr. 5: 13). Bez mierky.

k tomuto džbánku je z hrobu 143 na pohrebisku karpatskej mohylovej kultúry v Salke (obr. 4; Točík 1964, 29, obr. 5: 13; tab. XXVI: 3).

Zo severoslovenskej oblasti sú troma podobnými exemplármi zastúpené džbánky na pohrebisku v Martine: hroby 128, 135 a 137 (Benkovská-Pivovarová 1972, 263, 264, tab. XII: 6; XI: 1; XI: 9), ku ktorým však chýba výraznejší sprievodný 
inventár. K uvedeným typom džbánov sa hlási aj torzo nádoby zo sídliska v Liptovskom Michale, na ktorom sa tiež objavuje výzdoba obežnou líniou hrubších vpichov tesne pod rozhraním hrdla a tela (Veliačik 1983, 128, tab. I: 3). Súbor nálezov z tejto lokality je datovaný do stupňa BB2-BC1 (Veliačik 1983, 128). Do uvedenej kategórie možno priradit aj keramické nálezy z Liptovského Trnovca, hlavne z objektu 17 a 95 (Przybyła/Beljak 2010, 283-289, obr. 12: 1 ; 14: 2).

Za dnešného stavu bádania sa predpokladá, že na vzniku lužickej kultúry na Slovensku sa podiel'ali komponenty $\mathrm{z}$ troch kultúrnych prostredí, a to doznievajúce sporadické osídlenie mad’arovskej kultúry, kolonizačné osídlenie z obdobia formujúcej sa stredodunajskej, resp. karpatskej mohylovej kultúry a kolonizačné osídlenie z obdobia zánikového horizontu otomanskej kultúry z východného Slovenska (Kujovský 2015, 178). Impulzom $\mathrm{k}$ tomuto prenikaniu mohla byt’ pravdepodobne prospekcia medi a iných surovín, ktorých ložiská sa v bohatom počte nachádzajú aj v masíve Nízkych Tatier.

Najpočetnejším druhom bronzovej industrie lužickej kultúry na Slovensku sú ihlice. Známe sú predovšetkým z pohrebísk, nie nepodstatnú čast’ tvoria aj ich náhodné nálezy a zriedkavejšie sú zastúpené $\mathrm{v}$ depotoch, ale len niektorými typmi. Tvarom hlavice a krčka, prípadne ich výzdobou vytvárajú ihlice početné typy a varianty, ktoré sa svojím výskytom vztahujú spravidla na užší časový horizont. Stávajú sa tak dôležitým nálezom pri datovaní uzavretých nálezových celkov.

Ihlice s gulovitou hlavicou a zosilnený kŕčkom (obr. 2: 2), predovšetkým vd’aka častému výskytu na pohrebiskách, sú najpočetnejšie zastúpeným typom aj v lužickej kultúre. Nález z Podturne zhodne s analogickou ihlicou z Chalmovej možno datovat' do obdobia neskorej mohylovej kultúry až včasného obdobia kultúry popolnicových polí BC2-BD (Novotná 1980, tab. 25: 582).

Ihlica s výrazne zosilneným nezdobeným kŕčkom má z typologického aspektu hlavicu, ktorú snád’ môžeme považovat' za hríbovitú (obr. 2: 4). Datovanie sledovaného artefaktu tiež spadá do obdobia neskorej mohylovej, resp. včasného úseku kultúry popolnicových polí BC2-BD. Nález z Podturne má najbližšiu analógiu v Luborči, hrob 2/73 (Veliačik 1983, tab. XXI) a v Novákoch (Veliačik 1983, tab. XVI: 7, 10).

Na lokalite v Podturni bol evidovaný aj sklenený korálik valcovitého tvaru (obr. 2: 11). V rámci kultúr popolnicových polí na Slovensku sú najpočetnejšie predovšetkým koráliky svetlomodrej alebo tmavomodrej farby, práve z územia lužickej kultúry. Vyskytujú sa jednak v hroboch pod mohylami, ale aj v plochých hroboch. Ich najväčšia koncentrácia sa viaže k hornému toku Nitry (Furmánek/Horňák/Mitáš 2009, 85). Na nedávno publikovanom, pomerne rozsiahlom pohrebisku lužickej kultúry v Ilave, sa koráliky objavili v relatívne malom počte. Našli sa v hroboch 33, 41 a 49 zo skla zelenobelasej a modrej farby (Benediková/Katkinová/Budinský-Krička 2016, 151, obr. 64).

Na obr. 2: 5 je zobrazená bronzová široká nízka cylindrická špirála, vyhotovená z bronzového drôtu so spätnou slučkou, ktorá sa mohla používat' najskôr ako vlasová ozdoba. Zrejme ide o šperk s dlhodobým používaním od obdobia včasných popolnicových polí, s vrcholom používania v období neskorých popolnicových polí (Benediková/Katkinová/Budinský-Krička 2016, 149; Kytlicová 2007, 86).

Na obr. 2: 6, 7 sú dva otvorené bronzové krúžky z tenkého drôtu. Slúžili ako vlasové ozdoby, resp. náušnice. Ak by sa našli spolu v jednom hrobe, dalo by sa uvažovat' o ich párovom požívaní. Na pohrebisku v Ilave ale neboli hojne zastúpené (Benedikovál Katkinová/Budinský-Krička 2016, 151).

Na obrázku 2: 8-10 sa nachádzajú fragmenty deformovaných bronzových ihlíc, resp. bližšie nešpecifikovaných predmetov, ktoré sú presnejšie nedatovatel'né.

Relatívne dlhá (až $35 \mathrm{~cm}$ ) ihlica s cibulovitou hlavicou sekundárne stočená do kruhu (obr. 2: 1) mohla pravdepodobne plnit funkciu nákrčníka, ktorý sa síce v náplni lužickej kultúry vyskytuje, ale pomerne zriedkavo (Makarová 2008, 89, obr. 12). Nevylučujeme však ani alternatívu, že dôvodom jeho sekundárnej úpravy bolo uloženie do urny. Podobne ohnutú ihlicu, ale s inou hlavicou (Nadel mit kleiner Kopfscheibe) publikovala z neznámej lokality M. Novotná (1980, tab. 45: 1049). Chronológii ihlíc s cibulovitou hlavicou sa v jednej svojej práci venovala Z. Stegmann-Rajtár (1994, 321-324) a dospela k záveru, že v rámci neskorej doby bronzovej sú nálezové celky s cibulovitou hlavicou typické pre jej starší úsek, konkrétnejšie pre staršie obdobie stupňa HB.

Na obrázku 2: 3 je zobrazená ihlica s okrúhlou (krúžkovou podla ruskej terminológie) hlavicou. Ide o predmet, ku ktorému sme nenašli analógie $\mathrm{v}$ širšom stredoeurópskom ani balkánskom priestore. Na druhej strane bohatá typová škála sledovanej ihlice sa vyskytuje na náleziskách na pravom brehu Dnepra, ktoré sú datované do tzv. predskýtskeho obdobia (Terenožkin 1961, 167, obr. 111: 8-14).

Z neznámej polohy z katastra obce Podtureň sa do ružomberského múzea dostali črepy, ktoré údajne pochádzajú z mladšej doby bronzovej (Eisner 1933-1934, 177). 


\section{DATOVANIE POHREBISKA}

Pohrebisko v Podturni bolo iba čiastočne skúmané, na súvislej ploche s rozlohou okolo $200 \mathrm{~m}^{2}$. Jeho celkový rozsah a počet ešte neodkrytých hrobov nepoznáme. J. Neudeckom zachránené objekty zrejme reprezentujú iba torzo niekdajšieho pohrebiska ludu lužickej kultúry. Na základe zachovaného dokumentačného materiálu možno iba konštatovat', že počiatky pochovávania na tejto nekropole možno klást' ešte do obdobia tzv. predlužického horizontu.
Najmladšie hrobové celky pravdepodobne patria už do začiatku doby halštatskej. O kontinuite, resp. diskontinuite pochovávania v Podturni, v dôsledku absencie údajov o zachránených keramických nálezoch, by bolo zatial' predčasné zaujat stanovisko. Možno to očakávat od budúceho revízneho výskumu. Cielom tejto štúdie je sprístupnit’ odbornej verejnosti archívne dokumenty z výskumu J. Neudecka, z druhej polovice 19. stor., ktoré sú v dôsledku absencie zachránených artefaktov jediným zdrojom informácií o sledovanej lokalite.

\section{LITERATÚRA}

Benediková/KatkinoválBudinský-Krička 2016 - L. Benediková/J. Katkinová/V. Budinský-Krička: Ilava, poloha Porubská dolina. Pohrebisko lužickej kultúry na strednom Považí. Bratislava - Nitra 2016.

Benkovská-Pivovarová 1972 - Z. Benkovská-Pivovarová: Die Anfänge der Lausitzer Kultur in der Slowakei im Lichte der Grabfunde aus Martin. Slovenská archeológia 20, 1972, 253-312.

Csécs 2019 - T. Csécs (szerk.): „Romert sokan, Floriánt csak kevesen ismerik". Rómer Flóris és Ebenhöch Ferenc levelezése 1845-1888. Győr 2019.

Eisner 1933 - J. Eisner: Slovensko v pravěku. Bratislava 1933.

Eisner 1933-1934 - J. Eisner: Prehistorický výskum na Slovensku a v Podkarpatské Rusi v r. 1932 a 1933. Sborník Muzeálnej slovenskej spoločnosti 27-28, 1933-1934, $166-189$.

Furman 2016 - M. Furman: Opevnenia na Liptove. Refúgiá, hradiská a hrádky od praveku po stredovek. Žilina 2016.

Furmánek/Horňák/Mitáš 2009 - V. Furmánek/M. Horňák/ V. Mitáš: Sklené koráliky v období popolnicových polí na Slovensku. Stav výskumu. Študijné zvesti Aú SAV 45, 2009, 79-90.

Kenner 1860 - F. Kenner: Beiträge zu einer Chronik der archäologischen Funde in der österreichischen Monarchie (1856-1858). Archiv für Kunde österreichischer Geschichts-Quellen 22, 1860, 225-424.

Kenner 1867 - F. Kenner: Beiträge zu einer Chronik der archäologischen Funde in der österreichischen Monarchie (1862-1863). Archiv für Kunde österreichischer Geschichts-Quellen 35, 1867, 1-218.

Kujovský 2015 - R. Kujovský: Lužický kultúrny komplex. In: V. Furmánek (zost.): Staré Slovensko 4. Doba bronzová. Nitra 2015, 174-184.

Kytlicová 2007 - O. Kytlicová: Jungbronzezeitliche Hortfunde in Böhmen. Prähistorische Bronzefunde XX/12. Stuttgart 2007.

Lhotsky 1945 - A. Lhotsky: Die Geschichte der Sammlungen. Festschrift des Kunsthistorischen Museums zur Feier des fünfzigjährigen Bestandes. Band II. Wien 1945.

Majláth 1873 - B. Majláth: Liptómegyei őstelepek. Archaeologiai Közlemények 9, 1873, 37-57.

Makarová 2008 - E. Makarová: Ženský kroj lužickej kultúry v dobe bronzovej na Slovensku. Pokus o rekonštrukciu na základe hrobových nálezov a depotov. Študijné zvesti AÚ SAV 44, 2008, 65-191.
Mihalik 1889 - J. Mihalik: Prähistorische Orte im Liptauer Komitat. Jahrbuch des Ungarischen Karpathen Vereines 16, 1889, 27-56.

Neudeck 1879 - J. Neudeck: Germanische Befestigungen des oberen Waagthales in Ungarn. Mittheilungen der Anthropologischen Gesellschaft in Wien 8, 1879, 273-277.

Neudeck 1880 - J. Neudeck: Germanische Befestigungen des oberen Waagthales in Ungarn. Mittheilungen der Anthropologischen Gesellschaft in Wien 9, 1880, 29-59.

Neudeck 1883 - J. Neudeck: A Quádok pénzei. Archaeologiai Értesítő 3, 1883, 83-98.

Neudeck 1889 - J. Neudeck: Sajógömöri éremlelet a XVI. századból. Archaeologiai Értesítő 9, 1889, 417, 418.

Neudeck 1894 - J. Neudeck: Tiberius útja az Aldunán. Archaeologiai Értesítő 14, 1894, 114-130.

Neudeck 1901 - J. Neudeck: Kiadatlan alsó-moesiai érmek. Archaeologiai Értesitő 21, 1901, 345-351.

Nevizánsky/Prohászka, v tlači-G. Nevizánsky/P. Prohászka: Funde und Fundorte des Komitats Liptov nach dem Brief von Julius Neudeck an Freiedrich Kenner. Tisicum, v tlači.

Novotná 1980 - M. Novotná: Die Nadeln in der Slowakei. Prähistorische Bronzefunde XIII/6. München 1980.

Polla 1996 - B. Polla: Archeológia na Slovensku v minulosti. Martin 1996.

Przybyła/Beljak 2010 - M. S. Przybyła/J. Beljak: Bronzezeitliche Siedlung von Liptovský Trnovec. Slovenská archeológia 58, 2010, 273-308.

Rómer 1870 -F. Rómer: Felszólítás ügyfeleinkhez. Archaeologiai Értesítő 3, 1870, 230, 231.

Seidl 1846 - J. G. Seidl: Chronik der archäologischen Funde in der österreichischen Monarchie. Österreichische Blätter für Literatur und Kunst 18/3, 1846, 137-142.

Stegmann-Rajtár 1994 - Z. Stegmann-Rajtár: Vývoj stredodunajských popolnicových polí v neskorej dobe bronzovej (HaB) a vznik halštatskej kultúry. Slovenská archeológia 42, 1994, 319-333.

Vítek/Churý/Struhár 2002 - P. Vítek/S. Churý/V. Struhár: Dejiny obce Podtureň 1331-2002. Podtureň 2002.

Terenožkin 1961 - A. I. Terenožkin: Predskifskij period na dneprovskom Pravoberežje. Kiev 1961.

Točík 1964 - A. Točík: Die Gräberfelder der karpatenländischen Hügelgräberkultur. Fontes Archaeologici Pragenses 7. Praha 1964.

Veliačik 1983 - L. Veliačik: Die Lausitzer Kultur in der Slowakei. Nitra 1983. 


\title{
Das Urnengräberfeld der Lausitzer-Kultur in Podtureň im Spiegel der Ausgrabung von Julius Neudeck
}

\author{
Gabriel Nevizánsky - Péter Prohászka
}

\section{ZUSAMMENFASSUNG}

Die Erforschung der archäologischen Denkmäler von Podtureň (ung. Pottornya) begann in den 1870er Jahren, als bei dem Eisenbahnbau bzw. sonstigen Erdarbeiten Denkmäler verschiedener Epochen ans Tageslicht kamen. $\mathrm{Zu}$ diesen gehört das im Jahre 1871 beim Eisenbahnbau entdecktes Urnengräberfeld von Podtureň. Obwohl über die Freilegung und die Gräber B. Majláth, J. Neudeck und aufgrund der Arbeit von Majláth auch J. Mihalik berichteten, wurden keine Zeichnungen über die Funde veröffentlicht.

Zum Glück berichtete J. Neudeck in einem Brief vom 18. November 1871 dem Direktor der Wiener Antikensammlung Friedrich Kenner über der Ausgrabung und verfertigte Zeichnungen der Funde bzw. der Lage der Gräber. Kenner sammelte die Berichte für den nächsten Band der Chronik der archäologischen Funde in der österreichischen Monarchie, der jedoch nie erschienen ist.

Der Name Julius oder Gyula Neudeck (Abb. 1) ist in der numismatischen bzw. archäologischen Forschung gut bekannt. Neudeck hat zahlreiche Beiträge in Archaeologiai Értesítő, Archaeologiai Közlemények sowie in der Numismatischen Zeitschrift und in den Mittheilungen der Anthropologischen Gesellschaft in Wien veröffentlicht. Wegen seiner militärischen bzw. konsularischen Laufbahn gibt es Akten im Wiener Kriegsarchiv (OeStA/KA Personalunterlagen, Grunbuchsevidenzen, Pionierkorps, 1851-55. 28. Heft, 5 Folio, Kt. 2442) sowie im Haus-, Hof- und Staatsarchiv (OeStA/ MdA AdmReg Personalunterlagen Folio 4 Neudeck). Nach diesen ist Neudeck im Jahre 1835 in Wien geboren. Er diente zwischen 1850 und 1862 im österreichischen Heer bei den Pionieren als Hauptmann. Nach seiner Abrüstung lebte er in Linz, dann heiratete er Hortenzia Szmrecsány und die beiden zogen nach Liptov. Im Jahre 1890 verließ Neudeck Podtureň und arbeitete als Ingenieur bei den Regulierungsarbeiten am Eisernen Tor. Ab 1895 lebte das Ehepaar in Sofia, wo er bis zu seinem Tod am 11. Juni 1909 als Konsularbeamter wirkte.

Julius Neudeck lebte von der Mitte der 1860er Jahre bis 1890 in Podtureň. In diesen Jahren hat er zahlreiche Funde gerettet und aus diesen entstand eine kleine Sammlung. Über das Schicksal seiner Funde stehen keine Angaben zur Verfügung. Neudeck berichtete in seinem Brief vom November 1871 auch über die Grabung in Podtureň. Mit dem Brief wurde auch ein Blatt mit gefärbten Zeichnungen an F. Kenner geschickt, welche die dort gemachten Funde bzw. die Fundlagen zeigen (Abb. 2). Dank dieser Zeichnungen war es möglich, die
Funde und das Urnengräberfeld zu analysieren. Obwohl sowohl Majláth als auch Neudeck über dem Gräberfeld berichteten, wurden die dortigen Funde nicht abgebildet. Nach Majláth waren die Urnen bronzezeitlich, dagegen bestimmte Neudeck die Funde als späteisenzeitlich bzw. römerzeitlich.

Besonders interessant ist der gezeichnete Krug mit trichterförmigem Hals und abgebrochenem Henkel (Abb. 2: 15). Er ist mit zwei um Hals und Bauch umlaufenden Punkreihen verziert, welche Verzierung aus dem Gefäßkörper herausstehenden halbkugelförmigen Knuspern umrahmen. Das Gefäß stammt aus dem Vorlausitzer Horizont. Nach Analogien aus der Südwestslowakei ist anzunehmen, dass es ein Beweis für die Migration der dortigen Bevölkerung nach Norden ist. Seine beste Analogie befand sich im Grab 143 des Gräberfeldes von Salka (Abb. 4), wo ein Gräberfeld der karpatischen Hügelgräberkultur freigelegt wurde. Aus dem nordslowakischen Gebiet sind noch drei ähnliche Krüge bekannt, welche in den Gräbern 128, 135 und 137 des Gräberfeldes von Martin ans Tageslicht kamen. In diesen Gräbern waren jedoch keine zeitbestimmenden Beigaben. Die Kugelkopfnadel mit geschwollenem Hals ist der häufigste Nadeltyp in den Gräberfeldern der Lausitzer Kultur (Abb. 2). Die engsten Analogien der Podtureňer Funde finden sich in Chalmová, Luborča Grab 2/73 und Nováky. Ihre Datierung fällt in die späte Hügelgräberzeit/frühe Urnenfelderzeit (Reinecke BC2-BD). Die Nadel mit pilzförmigem Kopf und mit geschwollenem Hals gehört ebenfalls in die späte Hügelgräberzeit/ältere Urnenfelderzeit (BC2-BD). In Podtureň kam auch eine zylindrische Glasperle zum Vorschein. In den slowakischen Lausitzer Gräberfeldern der Urnenfelderkultur sind gerade die hellen bzw. dunkelblauen Perlen die häufigsten. Die Spirale aus breitem niedrig zylinderförmigem Draht mit zurückgesetztem Ende wurde höchstwahrscheinlich als Haarschmuck getragen. Es handelt sich dabei um einen langlebenden Schmuck, welcher in den Gräbern der frühen Urnenfelderzeit erscheint, aber am häufigsten in der Periode der Späturnenfelderzeit vorkommt. Die offenen Ringe aus dünnem Draht wurden als Haar- oder Ohrschmuck getragen. Sie sind in Ilava in hoher Zahl vertreten. Die 8-10 dargestellten Nadelbruchstücke bzw. Überreste von Gegenständen mit unbekannter Verwendung sind undatierbar. Die Abb. 2: 3 zeigt eine Nadel mit Korallenkopf (anhand der russischen Terminologie). Zu diesem Stück fanden wir keine entsprechende Analogie, weder 
in Mitteleuropa, noch am Balkan. Andererseits veröffentlichte A. I. Terenožkin ähnliche Bronzenadeln mit breiter typologischer Skala aus dem linken Ufergebiet des Dnepr (Ukraine), welche in der Präskythenzeit genutzt wurden.

Abb. 1. Das Porträt von Julius Neudeck (Országos Széchenyi Könyvtár, Budapest).

Abb. 2. Podtureň. Neudecks Zeichnungen der Funde und Fundstelle (Kunsthistorisches Museum, Wien).

Rukopis prijatý 26. 3. 2021

Abstract translated by Péter Prohászka

Zusammenfassung übersetzt von Péter Prohászka

PhDr. Gabriel Nevizánsky, CSc.

Archeologický ústav SAV Nitra

Akademická 2

SK - 94921 Nitra

nraunevi@savba.sk
Zum Schluss können wir feststellen, dass in Podtureň die Funde eines in der Periode BC2/BD angelegten Gräberfeldes zum Vorschein gekommen sind, wo kontinuierlich (?) oder mit kleineren Pausen bis zum HB bestattet wurde.

Abb. 3. Podtureň. Situationsplan der Fundstelle (nach Neudeck 1880, Abb. 3).

Abb. 4. Der Krug aus dem Grab 143 von Salka (nach Točík 1964, Abb. 5: 13). Ohne Maßstab.
Mgr. Péter Prohászka, PhD.

Archeologický ústav SAV Nitra

Akademická 2

SK - 94921 Nitra

prohaszkapeter@freemail.hu 
